\title{
Development of "Medical Support Integration" Mode Architecture Design under the Background of Aging
}

\author{
Lexuan $\mathrm{Li}^{1}$ \\ ${ }^{1}$ Xiamen University Tan Kah Kee College, Xiamen, Fujian Province, 363105, China
}

\begin{abstract}
Based on the background of aging, the demand of social pension is increasing day by day. In the face of the continuous development of aging, the plight of shortage of pension resources. Based on the analysis of pension buildings at home and abroad, this paper puts forward a new mode of "Medical Support Integration" architecture, and summarizes the design points of the pension medical care combined architecture. The purpose of this paper is to provide a design basis for the construction of comprehensive and sustainable pension buildings, alleviate the plight of the elderly, and from the perspective of the elderly, fully consider the elderly physical and mental needs, improve the integration of medical and nursing care space, and create a paradise for the elderly.
\end{abstract}

\section{Research background}

\subsection{Aging population}

With the innovation of science and technology, and the continuous improvement of medical technology, people in both developed and developing countries are attaching more and more importance to health problems. Avoiding death and extending life by means of medical treatment, the decline of the mortality rate of the population and the fertility rate of the infants have brought about the phenomenon of global aging. And the expansion of the old age group will have different degrees of negative impact on many aspects of the society.

In Chinese society, the medical care level has been steadily improved, the total mortality rate has dropped from 22.2 to 7.2 per 10,000 population, and the average life expectancy of the population reached 75.3 years in 2015. It is predicted that the average life expectancy will reach about 80 years by 2050 . At the same time, the country's family planning policy, increasing social pressure and the changing attitudes of the young, as well as the declining birth rate of babies, have also contributed to the rising proportion of the elderly population in China. According to the National Assessment Report on Aging and Health in China published by the World Health Organization in 2016, it is predicted that by 2050, China will become the world's largest group of high-collar elderly people. [1] In addition, in China, population migration from countrysides to cities makes it difficult for empty nester to provide for the aged in rural areas, while in urban areas, the burden on ordinary families to provide for the aged is too heavy, which also makes the social medical and old-age security face great challenges.
Due to the single disorder of pension industry, the lack of medical resources and the increasingly serious aging problem, a new operation mode is urgently needed to solve the current social pension dilemma. Under the support of the market demand and national policies, the mode of "Medical Support Integration Nursing Building" has emerged at the right time. Some projects aiming at the integration of medical and pension resources for the elderly have been tried out in various regions. The construction of a comprehensive institutional building of "Medical Support Integration Nursing Building" mode will have far-reaching significance to solve the aging problem in China.

\section{2 "Medial Support Integration Nursing Building" Mode}

The capacity of traditional home-based care for the aged is constantly declining, and the medical service capacity of communities and institutions is insufficient. It is difficult for comprehensive hospitals to adapt to different provision of the age demand resources [2]. In the face of the pension (nursing house) dilemma caused by the separation of medical care and pension, the "integration of medical care and nursing" aims to combine the pension resources and medical resources, so as to realize the medical treatment in the pension buildings and the pension in the medical institutions [3], It will effectively solve the problems of elderly people's inconvenient medical treatment and uneven distribution of medical resources.

The mode of "combination of medical care and nursing" can be roughly divided into four forms: internal medical care, internal medical care, cooperation and integration of medical and nursing. The mode of setting up medicine in the nursing home relies on the building of 
nursing home and adds medical function. However, there is a lack of professional medical care, which is not conducive to targeted care for the sick elderly. However, medical institutions cannot meet the high-quality needs of the elderly. However, under the mode of medical and nursing cooperation, it is difficult to coordinate the details such as convenient transportation, cooperation and operation mode between the elderly care institutions and medical institutions, and it is easy to see a doctor.

"Integration of medical care and nursing" is a service mode integrating medical treatment, nursing, care and basic pension facilities, life care and barrier free activities. [4] we should carry out effective and reasonable integration and distribution of resources, and carry out targeted maintenance and medical care for selfcare elderly, semi self-care elderly, disabled elderly and hospice care elderly, and care for the physical and mental cultivation and medical care function of the elderly in their old-age life.

Under the background of the aging world, the architecture of integration of medical and nursing embodies the high adaptability of future aging design, and provides an effective solution to the problems of confusion and shortage of pension resources and uneven distribution of medical resources.

\subsection{The design point of the "Medial Care and Nursing" mode building}

With the integration of medical care and nursing as the core of the pension building, the elderly group as the service subject, the designer must deeply analyze the behavioral and psychological characteristics of the elderly group, understand the physiological, psychological and medical needs of the elderly group, explore the relationship between the elderly and the elderly building, and summarize the design concept and design mode of the medical care building, so as to achieve the goal of "medical and nursing one" The real livability and sustainable development of "integrated" pension system. [5]

With the gradual increase of age, human body function will inevitably occur a series of physiological degradation and even disease. Based on the physical condition and behavioral characteristics of the elderly, the principles of accessibility, safety and suitability for the elderly should be followed in the architectural space design. According to the health status of the elderly, we should provide targeted care, referral and hospice care services, and adjust the proportion of general care and medical care according to the health status of the elderly.

A good psychological state is the basic guarantee of the quality of life for the elderly. It is also an indispensable part of the design concept of the integration of medical and nursing care for the elderly to carry out the care for the psychological level of the elderly into the humanized design of the pension buildings. [6] The gradual weakening or even loss of the perception ability of the elderly will lead to the loneliness of the elderly. The psychological state of the elderly should be fully considered in the building for the aged and implemented to the design level. Different design methods should be used to alleviate the negative psychology of the elderly, so as to improve the quality of life for the elderly.

\section{Design principle}

\subsection{Site selection}

For pension buildings, convenient location, clear planning area and self-system, "medical and nursing function" configuration is perfect, flexible and applicable space combination form is the goal principle in the early planning of pension buildings. [7]

The site selection of nursing homes should follow the basic principles of safety, convenience and environmental livability. First of all, from the perspective of safety and traffic convenience, pension buildings need to fully integrate the surrounding resources, and choose the location with convenient transportation and good infrastructure. Such layout is conducive to the travel and social interaction of the elderly. Under feasible conditions, priority should be given to the location near the city center and large hospitals nearby. Relying on the existing medical resources, it is convenient for the elderly to seek medical treatment in time when the medical conditions of the nursing home cannot support the treatment of the elderly. Secondly, from the recuperation function of pension buildings, high-quality environment is an important factor in site selection. Flat terrain, sufficient sunshine environment, good natural landscape conditions and quiet site environment are not only conducive to the construction of buildings, but also create a high-quality environment for the elderly.

Based on the trend of global aging, from the perspective of urban planning, the site selection of building planning combining old and young is the best choice for sustainable development of medical and nursing integrated buildings. On the one hand, there are strict requirements for sunshine and land use conditions for elderly buildings and primary and secondary school buildings. The combination of the two is conducive to saving land. Secondly, due to the change of social roles, the elderly, out of their dependence on their families, will show their love and intimacy to children and adolescents. The proximity of schools can not only alleviate the loneliness of the elderly, but also facilitate the education of respecting the elderly in schools. [5] As shown in Fig.1, in the master plan, the nursing home and nursing home are arranged adjacent to each other. 


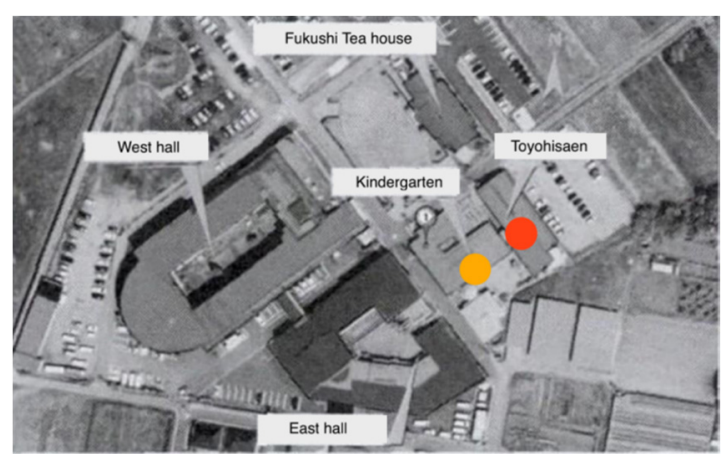

Fig.1 Site plan of the Toyohisaen

\subsection{Function configuration and spatial combination}

Compared with the ordinary pension institutions, the medical and nursing integration building adds medical services on the basis of it. Therefore, how to integrate the pension function and medical function in a building and organically connect the functional divisions of the building is the primary task of the medical care building. The main activities of the elderly in the building are daily living and leisure and relaxation. Therefore, special attention should be paid to the livable function of the elderly buildings in the design, so as to create a living space suitable for the elderly for self-care and leisure. The living space for self-care, semi self-care and disabled elderly can be partitioned to facilitate the medical work of nursing staff. In addition, medical space is also a major focus in the design of pension buildings. How to arrange the medical space, facilitate the rapid medical treatment of the elderly, and reasonably allocate medical resources according to the needs will play a basic role in ensuring the healthy life of the elderly. The following will be the overall function of medical buildings are roughly summarized into four parts: living maintenance area, medical care area, public activity area and auxiliary administrative area.

Table 1 Functional classification

\begin{tabular}{|c|c|}
\hline Function partition & Main function \\
\hline Living care area & $\begin{array}{c}\text { Daily live, dining space } \\
\text { bath, basic nursing }\end{array}$ \\
\hline Medical care area & $\begin{array}{l}\text { Health care, treatment } \\
\text { ICU, pharmacy, } \\
\text { operating room、clinic }\end{array}$ \\
\hline Public activity area & $\begin{array}{l}\text { Dining hall } \\
\text { entertainment, social } \\
\text { space、 banquet hall. } \\
\text { multi-function hall. } \\
\text { gym、cheesing room、 } \\
\text { poor }\end{array}$ \\
\hline Auxiliary office area & $\begin{array}{c}\text { Equipment room、 } \\
\text { meeting room、 Office、 } \\
\text { dormitory }\end{array}$ \\
\hline
\end{tabular}

The living care area is the most private part of the geracomium building. For the elderly with different physical quality, they are assigned to live in different living maintenance areas, such as self-care area, nursing care area and assistance area. Different types of elderly living in different areas are conducive to the medical efficiency of nursing staff. The living maintenance area is the most private part of the pension building. For the elderly with different physical quality, they are assigned to live in different living maintenance areas, such as selfcare area, nursing care area and assistance area. Different types of elderly living in different areas are conducive to the medical efficiency of nursing staff. The medical maintenance area should reasonably allocate medical resources and clarify the flow line of medical treatment, which is helpful for the elderly to seek medical treatment in time and ensure their health. The public activity area has open space characteristics, and the elderly can carry out social activities in this space. The auxiliary administration should have its own system and independent streamline, so as not to disturb the living space of the elderly.

In order to make the function of each division clear, streamline clear, form a relatively independent and interconnected organic whole, we can consider the use of centralized, decentralized and mixed spatial layout.

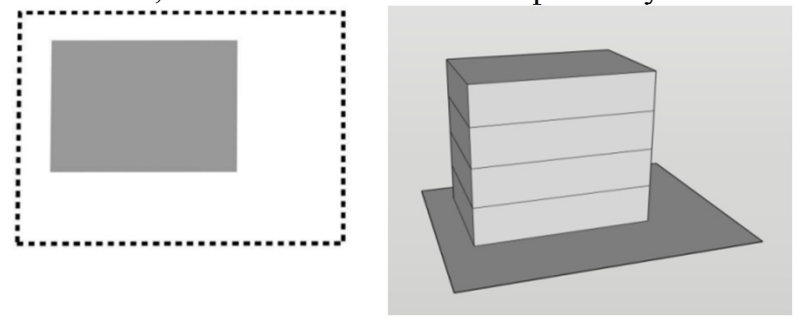

Fig.2 sketch map of the centralized spatial layout

As shown in the Fig.2, centralized layout means that all functional configurations are concentrated in one building, different functional spaces are vertically superimposed, and each floor functional area is connected by traffic box. According to the degree of disability of the elderly, the intervention floor, nursing floor and self-care floor were set from low to high. [9] According to the demand of medical treatment level, the medical units should be set up reasonably. In addition, due to the closed nature of the centralized building, appropriate addition of atrium and hanging garden is also conducive to the internal environment of the building and the physical and mental relaxation of the elderly. It is suitable for the small-scale and limited use area of the pension base, and it is also convenient for institutions to centrally manage each functional area.
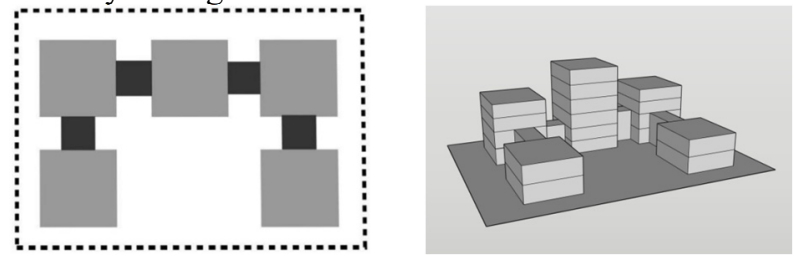

Fig.3 Sketch map of the decentralized spatial layout 
As shown in Fig.3, in the decentralized layout, the living care area, medical care area, public activity area and auxiliary administrative area are arranged in different areas. The corridor or outdoor traffic box is used to connect each other. Each area is independent, with clear division and clear flow line. However, attention should be paid to the design of green channel with the medical functional area, so as to timely send patients in case of emergency. Moreover, due to the decentralized layout, the design ability of courtyard greening is improved, which is also conducive to creating a high-quality external environment of the building, which is conducive to the comfortable and pleasure old age live. It is suitable for the large-scale and abundant old-age care base.
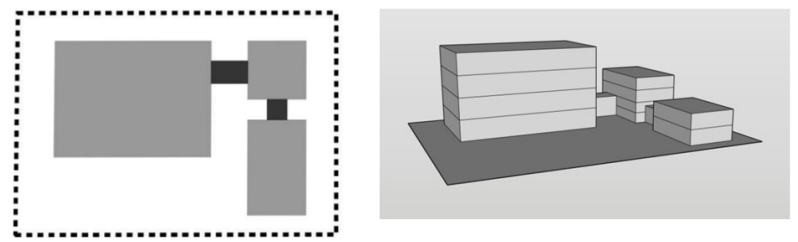

Fig.4 sketch map of the mixed spatial layout

As shown in Fig.4, in the mixed layout, one part of the functional area is centralized, and the other part is distributed. This mode combines the advantages of the former two. Part of the functions are centralized for management, and some functions are arranged separately without disturbing each other. Thus, the assumption of mutual independence and mutual connection is realized. In the form of architecture is also more rich, breaking the

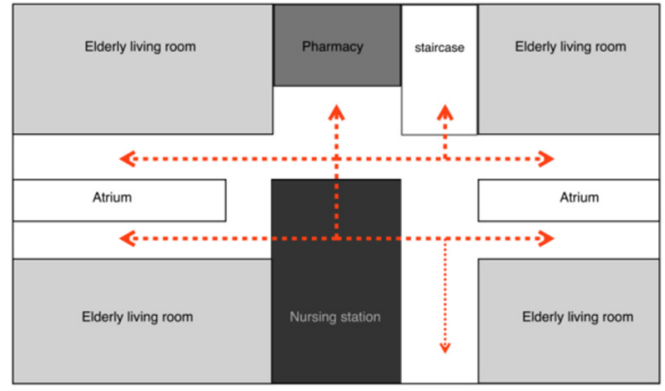

Fig.6 Nursing station plan in Japan

as the fig.6 and fig.7, the nursing unit layout of some nursing homes in Japan and the United States is arranged, it is a space for nursing staff to be on duty and provide nursing services for the elderly [8]. It is an indispensable and important part of the pension building, and is the basic guarantee for the healthy pension of the elderly. The design of nursing station in the facilities for the aged should follow two basic principles: unobstructed vision and fast accessibility. The purpose of sight unobstructed traditional rules of the nursing home boring architectural layout

\section{3unit plane function design}

- The malpractice of the plane design of the traditional nursing home

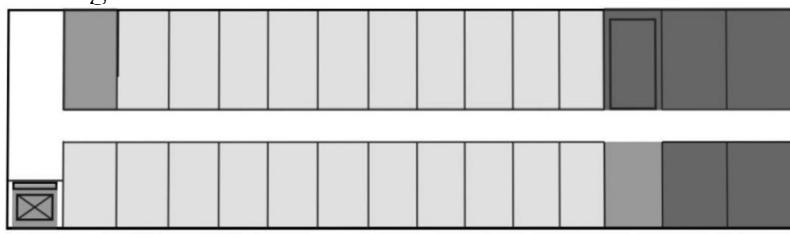

$$
\begin{aligned}
& \text { Elderly living room } \\
& \text { Transportation box } \\
& \text { Medical center \& Nursing station }
\end{aligned}
$$

Fig.5 Chinese traditional plane function design

As the Fig.5, Chinese traditional nursing homes are mostly rebuilt from hospitals or schools, with linear layout on the plane and regular layout along both sides of the corridor. The architectural space is rigid and monotonous, with strong closure and poor lighting. The medical unit is located at one end of the corridor, which does not meet the requirements of visibility and accessibility of nursing station. There is a lack of activity space in the unit, and the parking space is small. Too rigid and boring building space is not conducive to the mental health of the elderly.

- Nursing unit

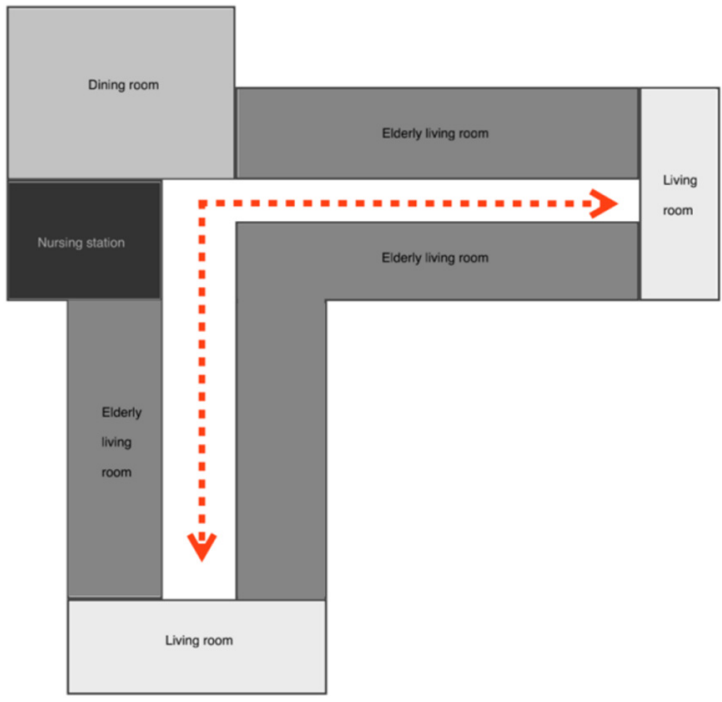

Fig.7 Nursing station in American Nursing Home

is that the nursing staff can know the behavior dynamics of the elderly within the visual range in the nursing station, so as to ensure that the nursing staff can grasp the activity status of the elderly in time. The purpose of fast accessibility is to shorten the service distance, improve the efficiency of nursing, and help nursing staff to deal with emergencies in time. 


\section{- Medical unit}

With the increase of the age of the elderly, the medical unit is responsible for the monitoring and management of the health of the elderly and the prevention of emergency treatment. It is a particularly important functional unit in the integrated medical and nursing building.

The medical unit provides the elderly with health care, health examination, routine disease examination, nursing care, special disease monitoring and hospice care and other services for the elderly. There are problems such as the interwoven flow line of medical care and the flow line of the elderly, the complex medical function and the large flow of personnel. The reasonable and clear space arrangement of the consulting room in the medical unit and the simple and clear guiding flow line are the important premise to ensure the orderly medical work.

The medical unit belongs to semi private functional space. In the plane layout, the demand of dynamic and static partition and separation of cleaning and pollution should be taken into consideration. A certain sanitary distance should be kept from the kitchen space. The indoor layout should desalinate the medical atmosphere and create a kind and quiet diagnosis and treatment environment for the elderly. [11]

- Activity unit

Due to the change of body function and social role, the old people have a sense of psychological gap. From the perspective of psychological care for the elderly, the multi-level and multi-functional design of the activity unit in the pension building is conducive to the elderly to improve their loneliness, increase their life interest, and help them fill in the social emptiness and maintain their social value.

Different from nursing unit and medical unit, activity unit is a kind of social public activity space which can be opened to the public, and a multi-functional place for various leisure and entertainment activities. As a gathering place for the elderly, the activity unit should ensure sufficient sunshine and daylighting, and good ventilation. According to the different types of activities, dynamic and static activity areas are set up for the elderly to choose. The interaction between indoor activity unit and outdoor activity space can improve the living happiness of the elderly.

\subsection{Optimal aging design}

In the integration of medical and nursing buildings, the aging space has comprehensive, experiential and temporal design features. That is, according to the elderly's multi-faceted (physiological and psychological, social and self) matching of multi-cultural functional facilities, to improve the elderly in the process of continuous aging caused by the inconvenience of movement, sensory aging and other functional degradation caused by residential problems [10].

With the growth of age, the range of activities of the elderly is gradually shrinking, and the living room and bedroom become the places where they use the most time. [11] The living room space should be far away from the noisy environment, keep a certain quiet distance from the public activity space, and set up a green channel between the room and the medical space, with sufficient sunshine and daylighting, and good ventilation. There is enough space in the room, at least to ensure that the wheelchair can move freely in the room. Make full use of building components and various pension equipment to meet the physical medical needs of some elderly people with special diseases.

As Fig.8 to 9, according to the human engineering of elderly, the principle of barrier free design is fully implemented in the aging design part of architectural design.
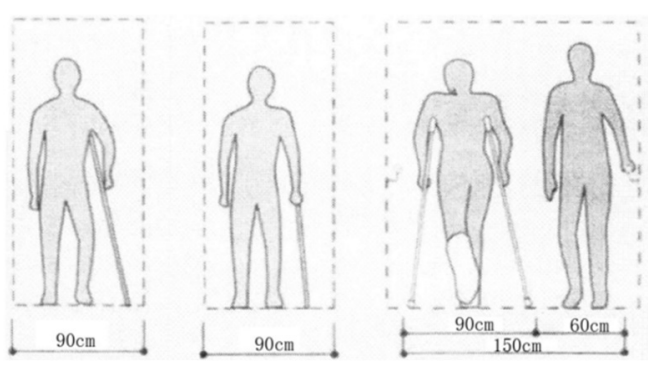

Fig.8 Ergonomics of the elderly, Old man on crutches

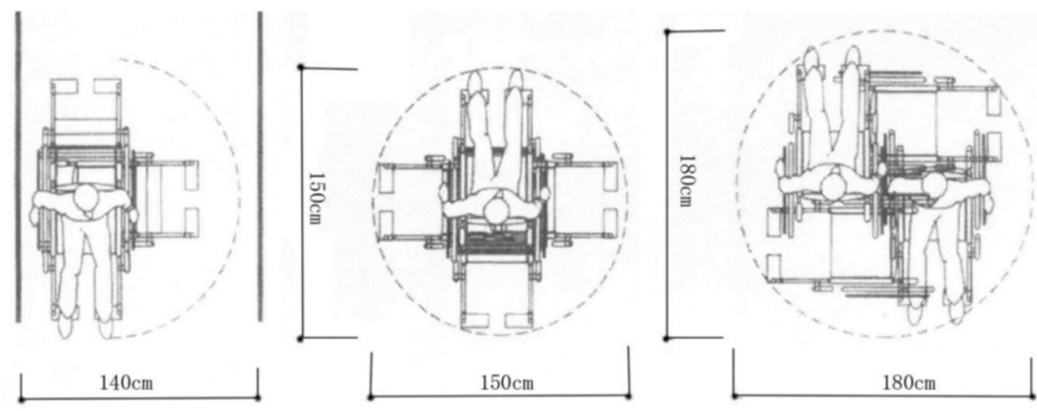

Fig.9 Ergonomics of the elderly, Device-aided elderly 
With the growth of age, the range of activities of the elderly is gradually shrinking, and the living room and bedroom become the places where they use the most time. [11] The living room space should be far away from the noisy environment, keep a certain quiet distance from the public activity space, and set up a green channel between the room and the medical space, with sufficient sunshine and daylighting, and good ventilation. There is enough space in the room, at least to ensure that the wheelchair can move freely in the room. Make full use of building components and various pension equipment to meet the physical medical needs of some elderly people with special diseases.

In the living room and public toilet, it should be considered to set up care toilet room for the elderly with poor mobility. The entrance and exit of bathroom space and the space in toilet should meet the scale of wheelchair access. The bath equipment adopts adjustable mode to adapt to different types of elderly people. Waterproof and antiskid materials are selected for floor decoration to prevent accidents of the elderly. In addition, the wheelchair, operating bed and various medical equipment should be fully grasped to ensure the space scale for the elderly with mobility problems. Public space transparency design, on the one hand, the open space is conducive to the communication between the elderly, and on the other hand, it can also ensure that the caregivers grasp the activity dynamics and deal with some emergencies in a timely manner.

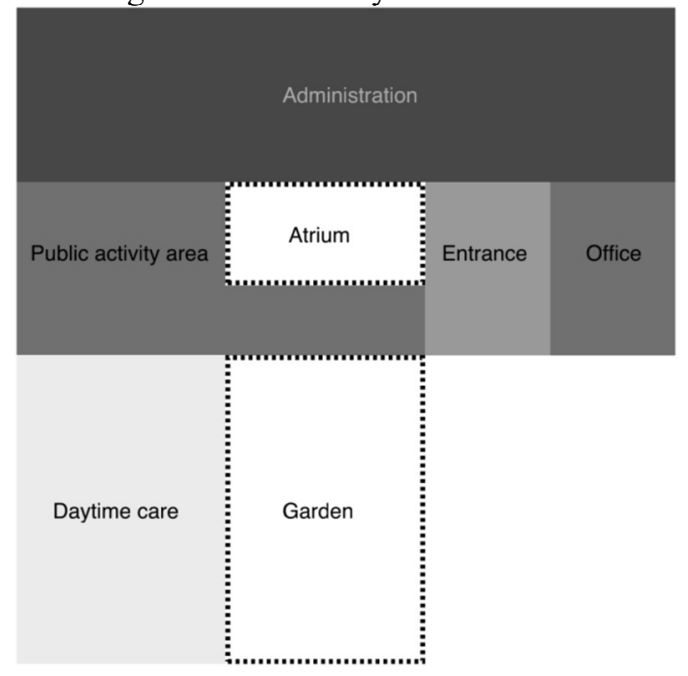

Fig.10 The plan of Mashisaen

"Layout in clusters" is an important development feature of special care homes for the elderly in Japan. It has the advantages of reducing the nursing unit. It is convenient for the elderly living in Japan to communicate with each other. On the other hand, it is conducive to the nursing staff to monitor the living conditions of the elderly living in Japan and provide targeted nursing services. [12] The "Layout in clusters" mode in Mashisaen shows that the living floor is divided into four groups and there are separate rooms for 12-13 elderly people to live in. In order to emphasize the domain sense of small unit living space and enhance the family atmosphere, the design specially sets a porch in each group to make the elderly feel home.

\section{Case analysis}

\subsection{Mashisaen nursing home, Japan}

Compared with China, Japan has entered an aging society much earlier. In solving the problems of social pension and the construction of nursing homes, Japan has to be more mature, and gradually forms its diversified and multi-level pension system. Therefore, the research and analysis of the old-age buildings in Japan will be of great help to the transformation and improvement of China's pension facilities. In this paper, the author investigates and analyzes Mashisaen, which is located in Kawagoe City, Saitama Prefecture, Japan. It covers an area of 5972 square meters and can accommodate 100 elderly people. In addition to providing special maintenance services, zhenshou garden also has a day care center, which provides a place for some elderly people to take part in day activities.

As shown in Fig.10, the building adopts "L" layout, with courtyard in the South and facing the woods, which creates a good natural view for Mashisaen. The building is divided into three floors. The first floor is the public activity area and auxiliary administrative area. The second and third floors are the residential area and nursing area for the elderly.

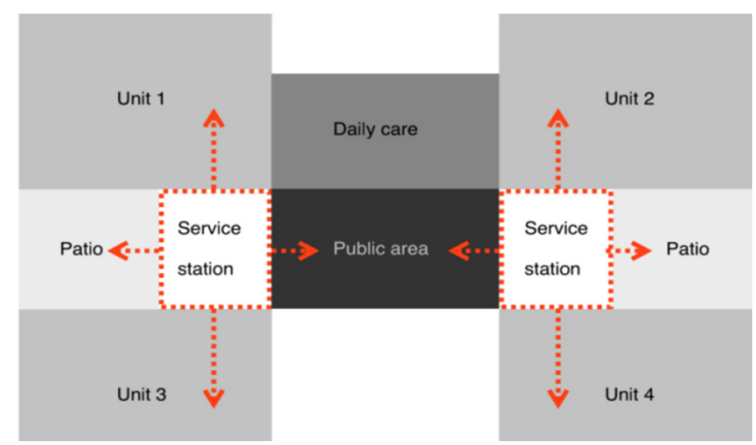

Fig.11 Nursing floor of the unit plan

In addition, as the fig. 11 , there is a separate nursing unit in each group, and special nursing staff are responsible for the meals and daily activities of the elderly in the group. It can reduce the service intensity of two groups, such as the service of two groups, and reduce the service intensity of two groups. Formed a convenient and effective service management space [12].

In space design, Mashisaen nursing home has designed an open main entrance space to provide reception, display and rest functions. Home facilities are arranged around, leaving a complete and open activity area in the middle. On the one hand, it is convenient for personnel to collect and distribute, on the other hand, it also makes the space and space keep good connectivity, 
eliminating the sense of closeness of the space. In activity space, the designer has created a variety of leisure space for the elderly. Considering the different activities and preferences of the elderly, four different seat forms are designed in the public space for them to choose, providing different activity functions, so that the elderly can freely choose. At the same time, it respects the diversity of elderly people's living space, and at the same time, it also ensures the independence and safety of the elderly.

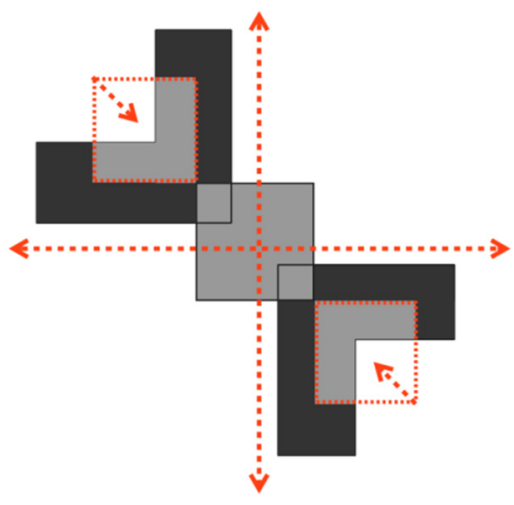

\subsection{Centrality design}

In developed countries, such as the United States, the research on pension buildings is much more mature than that in China. In order to make the service streamline short and improve the service efficiency, the "group type" layout mode is summarized to optimize the design of pension buildings. The specific operation method is to form a small-scale unit group of 8-10 nursing and semi nursing elderly living space, and the nursing station and activity space are dispersed in the elder unit group. [13] For example, the evergreen retirement community in the United States and the Nuremberg mental retardation rehabilitation center.

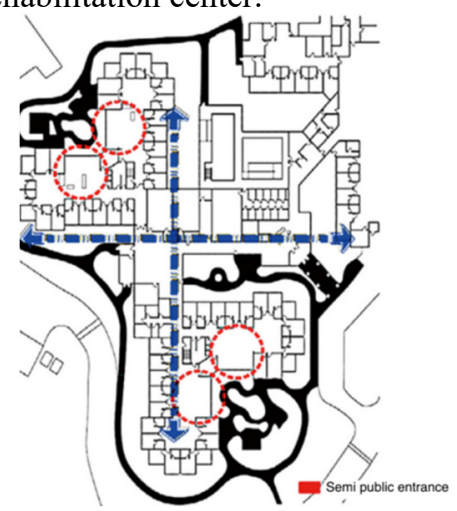

Fig.12 The evergreen retirement community

As the Fig.12, the evergreen retirement community in the United States mainly serves the elderly over 55 years old in the community. It is committed to meet the special needs of the elderly and assist in completing difficult daily activities, so as to provide a comfortable and safe living environment for the elderly. The living room for the elderly is composed of two "L" type oblique directions, and 11 single room apartments are arranged centripetally to form a central public activity atrium for the elderly. In addition, it is also used as a transportation hub connecting different units, making the relatively independent unit space organically linked. Encourage the elderly to carry out some social activities in this space, increase the daily interaction, but also facilitate the centralized management of nursing staff. [13]

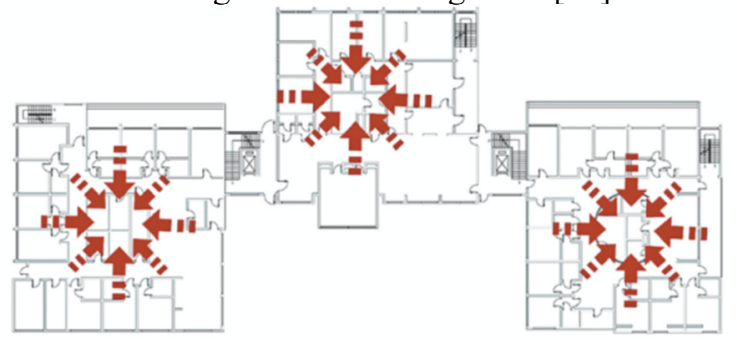

Fig.13 The Nuremberg mental retardation rehabilitation center

As shown in Fig.13, Nuremberg mental retardation rehabilitation center is a German non-profit organization which combines medical care and nursing. It is a five stories building for 96 people. The building is divided into three square houses connected with each other. On the plane, the three square planes in rectangle shape are respectively a unit space, which can be used by 12 patients. In the whole space organization, the middle plane is the core, which shortens the round-trip distance of nursing and improves the nursing efficiency. The unit space organization takes the central activity area as the core, which is convenient for residents to travel and convenient for centralized nursing. In addition, the space of the zigzag courtyard provides a resting interior garden for the building, which increases the green area of the building.

\section{Conclusion}

Under the background of global aging, in the face of social Elderly Nursing Care dilemma, to improve the quality of the life in retirement for the elderly, "Medical Support Integration Nursing Building" mode emerge as the time. In order to better combine the medical and pension functions, build a high-efficiency and livable medical and nursing integrated pension building, this paper starts from the needs of the elderly, fully considers the site selection, functional configuration, aging design and other aspects, combined with the advantages of foreign mature building examples, summarizes the following suggestions and key points.

(1) Based on the sustainable development of nursing buildings, in the early stage, the site selection planning should fully consider the traffic network, supporting facilities, site location and environment conditions. Generally, the location should be located in the area with convenient transportation, nearby medical resources and pleasant environment, which will be conducive to the follow-up development of pension buildings. 
(2) In the building, it is necessary to clearly distinguish the functional zoning of each part, ensure the convenience and independence of different traffic flow lines, and reasonably allocate the pension resources and medical resources, which will effectively improve the efficiency of nursing work and ensure the life and health of the elderly.

(3) The building for the aged is not only a place for the elderly to live in their old age, but also should be concerned about their psychological needs, so that the elderly can fully feel the warmth of their old age life, which is the goal of a modern humanized nursing building.

\section{References}

1. World Health Organization, National assessment report on aging and health in China, (2016)

2. ZHANG Feifei, Research on the Design of Pension Institutions under the Combination of Medical and Nursing[D], (2018)

3. QI Peng, Research on Space Design of MedicalMaintenance Integrated Old-age Building —-Take Changsha City as an Example[D], (2019)

4. CHEN Ning, Development Experience of "Medical Support Integration" Service Mode in Foreign Countries and Its Enlightenment to China [A], China Pharmacy, (2017),28-11:1441-1444

5. FAN Yihui, Several Attentions Paid to Design of Aged Care Building Starting from Need of Elderly People[B], Building Construction, (2015), 37-11: 1322-1324

6. FU Kai, QIAN Xiao, Architecture Especially Designed for Aged to Meet their Psychology Needs[A], Hundred Schools in Artist, (2011), 7:9496

7. YANG Yezhen, A preliminary study on the design strategy of the old-age building under the mode of "Medical-nursing combined" [D], (2018)

8. ZHOU Yanmin, LI Jiajing, Research on Nursing Station Design in Elderly Facilities[J], Architecture Technique, (2014),98-102

9. QI Peng, Research on Space Design of MedicalMaintenance Integrated Old-age Building —-Take Changsha City as an Example[D], 2019

10. JIAO Yan, Medical and Old-age Care Integrated Discussion on New Application on Space Design for Aging Community_-Suzhou Yangcheng Lake to China Life Pension and Health Project as an Example[A], Design, (2020),3: 62-65

11. YU Zhihong, Design of Pension Building Space based on the concept of suitable aging[D], Industrial Construction, (2016), 8:56-60

12. ZHOU Yanmin, LI Jiajing, Elderly Facility Architecture Design by the Concept of Humanization: Case Study of Elderly Facilities in China and Japan[J], Art\&Design, (2012),9:32-37
13. BU Deqing, FENG Menjiao, Application of Psychological Impacts of the Spatial Environment Design of Aged Care Buildings[A], Huazhong Architecture, (2016), 10:178-182 